\title{
ELECCIONES PRIMARIAS Y PERSONALIZACIÓN DE LA POLÍTICA. El CASo de las elecciones locales en ChILe 2012*
}

Primary Elections and Personalization of Politics: The Case of Local Elections in Chile 2012

\section{CARLOS CANTILLANA PEÑA}

Universidad Diego Portales

\section{GONZALO CONTRERAS AGUIRRE}

Universidad Diego Portales

\section{MAURICIO MORALES QUIROGA}

Universidad Diego Portales

\begin{abstract}
RESUMEN
Aunque las elecciones primarias han sido popularizadas como el mecanismo de selección de candidatos más abierto y participativo, muchas veces generan el efecto contrario, fortaleciendo la personalización de la política y no la institucionalización de los partidos. Estudiamos las elecciones primarias de Chile organizadas por la coalición de centro-izquierda Concertación, para elegir sus candidatos a alcalde en 2012. Sostenemos, en primer lugar, que a mayor fuerza electoral del candidato incumbente, menor participación. En segundo lugar, que la participación en la elección general fue casi idéntica entre comunas donde se hicieron y no se hicieron primarias. En tercer lugar, que las primarias mejoraron la elegibilidad principalmente de los desafiantes. En consecuencia, las primarias no estimularon la participación, pero sí contribuyeron al éxito de los candidatos.
\end{abstract}

Palabras clave: Elecciones primarias, participación, elegibilidad, incumbencia, Chile.

\begin{abstract}
Although the primaries have been popularized as the mechanism for selecting candidates more open and participatory, often generate the opposite effect, strengthening the personalization of politics and not the institutionalization of parties. We study the primaries of Chile made by the coalition of center-left (Concertation) to choose their candidates for mayor in 2012. We argue, first, forcing major electoral candidate incumbent, reduced turnout. Secondly, that the voter turnout in the general election was almost identical between communes where were and were not primary. Thirdly, that primaries improved eligibility mainly on the challengers. In consequence, the primaries did not stimulate turnout, but contributed to the success of the candidates.
\end{abstract}

Key words: Primaries elections, turnout, eligibility, incumbency, Chile

* Agradecemos los comentarios de los tres árbitros anónimos de RCP. Naturalmente, los errores u omisiones son de exclusiva responsabilidad de los autores. Este artículo se enmarca en el proyecto de investigación titulado "A Crisis of Legitimacy: Challenges to the Political Order in Argentina, Chile and Uruguay", financiado por el International Development Research Centre (IDRC). 


\section{INTRODUCCIÓN Y ARGUMENTO}

¿Son efectivamente las primarias un mecanismo de selección de candidatos (MSC) que fortalece a los partidos y que estimula la participación electoral?, ¿quiénes votan en las primarias?, ¿qué efecto tienen las primarias sobre la elegibilidad de los candidatos? Respondemos estas preguntas tomando como caso de estudio las elecciones primarias locales de la coalición de centro-izquierda (Concertación) en Chile realizadas en abril de 2012. La importancia del caso es que estas elecciones se hicieron en un contexto institucional de voto voluntario, con primarias voluntarias, sin regulación estatal, y sin financiamiento público de las campañas. Es decir, casi en un "estado de naturaleza". Si bien Chile ha sido reconocido como uno de los sistemas de partidos más institucionalizados de América Latina (Mainwaring y Scully, 1995; Payne et al., 2003), las elecciones primarias locales de 2012 entregan más evidencia de personalización de la política que de fortalecimiento partidario. Para estudiar el caso utilizamos datos electorales e información de fuentes directas que corresponden a dirigentes políticos de esta coalición que participaron activamente del proceso de primarias. ${ }^{1}$

Existe cierto consenso en que las primarias contribuyen a la participación electoral (Navia y Rojas, 2008; Kanthak y Morton, 2003; Serra, 2008 y 2011) y a la elegibilidad de los candidatos (Rahat y Hazan, 2001; Carey y Polga-Hecimovich, 2006; Carey, 2008; Jackson et al., 2007; Serra, 2011). ${ }^{2}$ La literatura sobre primarias en América Latina tiende a subrayar los efectos positivos de este MSC en las instituciones democráticas (Alcántara, 2002; Carey, 2008; Valdez et al., 2010). En especial, se destaca su impacto en dos esferas básicas: participación y competencia (Freidenberg, 2003; Barreda, 2004). Haciendo generalmente alusión a las elecciones presidenciales en Uruguay, se asume que las primarias van de la mano con la solidez de su sistema de partidos y la calidad de su democracia (Altman, 2012). En otras palabras, las primarias se constituyen en un MSC que estimula tanto el involucramiento ciudadano en la política como la competencia electoral dentro de los partidos (Pennings y Hazan, 2001).

Para otros, sin embargo, las primarias pueden generar el efecto contrario, deprimiendo la institucionalización del sistema de partidos y fortaleciendo la personalización de la política. Según Rahat "inclusive methods also seem to encourage the politics of personality and may thus lead to low levels of party cohesion"(2009: 166). Evaluamos el caso de Chile en esta perspectiva considerando las dimensiones de participación y elegibilidad. Las primarias se desarrollaron en un ambiente de baja confianza hacia los partidos (Encuesta Universidad Diego Portales, 2013; Encuesta del Centro de Estudios Públicos, 2013). Por tanto, era más o menos esperable que lucieran los líderes o caudillos

1 Por cierto, no podemos revelar la identidad de estas personas debido a que la información suministrada fue bajo el secreto de la fuente. Entrevistamos a 8 dirigentes políticos de la Concertación entre el 8 de enero 2013 y el 18 de marzo 2013.

2 Según Carey (2008), los candidatos elegidos en primarias obtienen un "bono" que circula entre $4 \%$ y $6 \%$ de apoyo, lo que denomina como el "bono de primarias". 
locales, generalmente incumbentes, y no los partidos como instituciones encargadas de representar a los ciudadanos. ${ }^{3}$

Las primarias municipales de la Concertación se realizaron el 1 de abril de 2012, casi siete meses antes de las elecciones generales. Estas primarias se desarrollaron en 141 de 345 comunas del país y representan alrededor del 50\% de la población del país. La participación fue de 315 mil personas, lo que representó, aproximadamente, $10 \%$ respecto del total de personas habilitadas para votar en esas comunas. Otro cálculo indica que, de acuerdo con la votación que obtuvo la Concertación en las municipales de 2008, esas 315 mil personas equivalen casi al 25\% de los votos concertacionistas. Es decir, para las primarias votó uno de cada cuatro simpatizantes de la Concertación.

En función de estos antecedentes, planteamos tres preguntas centrales:

a) ¿Qué características tuvo la participación en las elecciones primarias?

b) ¿En qué medida la participación en primarias explica la participación en la elección general?

c) ¿Son las primarias un predictor de éxito para candidatos incumbentes y desafiantes?

Nuestras preguntas de investigación se fundamentan en las principales inquietudes teóricas discutidas en la literatura sobre el efecto que tienen las elecciones primarias tanto en la participación como en el resultado de la elección general (Colomer, 2002; Carey, 2008; Carey y Polga-Hecimovich, 2006; Navia y Rojas, 2008; Ramiro, 2014).

El artículo se divide en cuatro secciones. En la primera mostramos un panorama general de la teoría de elecciones primarias, colocando especial atención a sus efectos acerca de la participación y la elegibilidad de los candidatos. En la segunda analizamos las primarias de la Concertación con particular énfasis en las variaciones de la participación electoral, explicándola en función de las características socioeconómicas de las comunas y de la competencia entre los candidatos. En la tercera estudiamos el efecto de la participación en las primarias respecto de la participación en la elección general. En la cuarta, evaluamos el éxito de candidatos incumbentes y desafiantes comparando los que fueron y no fueron a primarias.

\section{TEORÍA SOBRE PRIMARIAS}

Un aspecto fundamental en cualquier elección es la nominación de los candidatos (Jackson et al. 2007; Freidenberg, 2003). Estos procesos pueden realizarse mediante múltiples mecanismos. Puede ser que los líderes de los partidos designen directamente a sus candidatos; que se escojan en una asamblea partidaria; que se realice una convención o junta del partido para que sus militantes diseñen un mecanismo de selección de candidatos; puede realizarse una asamblea o convención nacional donde se designe al candidato;

3 Algo distinto ha sucedido en Islandia. A pesar de que el mecanismo de primarias es utilizado desde la década de 1970, los partidos no han perdido cohesión (Indridason y Kristinsson, 2014). 
o pueden realizarse elecciones primarias (Carey, 2008; Rahat, 2009; Jackson et. al., 2007; Freidenberg, 2003). Según el "selectorado"4 que participe de la elección del candidato, es posible hablar de MSC inclusivos y exclusivos (Rahat y Hazan, 2001; Kenig, 2009; Toro y García, 2008; Colomer, 2002), los que pueden ir desde el electorado total de un país (inclusivo) a solamente la élite partidaria o los militantes de un partido (exclusivo).

Los estudios sobre elecciones primarias se han concentrado en las primarias presidenciales o parlamentarias. Es así para los trabajos que estudian el caso de Uruguay (Altman, 2012; Buquet y Chasquetti, 2008; Buquet y Piñeiro, 2011), México (Valdez et al., 2010; Langston, 2009; Bruhn, 2010), Canadá (Johnston et al., 2007; Kenig, 2009), Estados Unidos (Lengle et al., 1995; Jacobson, 1981; Geer, 1998), las primarias realizadas en América Latina (Carey, 2008; Carey y Polga-Hecimovich, 2006; Colomer, 2002; Freidenberg, 2003) o en democracias industrializadas (Indridason, 2008; Jackman y Miller, 1995; Kenney y Rice, 1985; Mikulska y Scarrow, 2010). La investigación sobre elecciones primarias locales es escasa. Los trabajos de Carty y Eagles (2003) sobre Canadá y Ramiro (2014) sobre el caso del Partido Socialista Obrero Español (PSOE) son de los pocos estudios que miden el impacto de las elecciones primarias en las elecciones locales. Ambos muestran el beneficio electoral de la realización de primarias.

\section{Ventajas, desventajas y contexto en que se realizan primarias}

La ventaja principal de la primaria es que permite conocer las habilidades de los candidatos frente a la elección general (Serra, 2008 y 2011). En efecto, los candidatos tienen que responder a los requerimientos de la ciudadanía, de los periodistas, eventualmente deben asistir a debates y hacer campaña. Igualmente, las elecciones primarias son una buena instancia para "descubrir" candidatos que inicialmente eran marginales o invisibles. Buen ejemplo de ello son Barack Obama y J. F. Kennedy en Estados Unidos, o Ségolène Royal en Francia (Serra, 2008). Adicionalmente, se ha argumentado que las elecciones primarias contribuyen a la legitimidad del candidato (Rahat, 2009; Colomer, 2002). Para algunos, incluso, una primaria abierta puede otorgar "doble legitimidad" al ganador, pues no solo contará con el respaldo de los militantes, sino que también de los independientes. Esto lo colocaría en mejor posición frente a la elección general (Rahat y Hazan, 2001). Además, las primarias entregan a la ciudadanía un mensaje de mayor transparencia (Morgenstern y Siavelis, 2008; Navia y Rojas, 2008), lo que genera un efecto publicitario positivo en el electorado (Alcántara, 2002; Boix, 1998).

Entre las desventajas de las primarias, en tanto, está el desgaste que se produce en un partido o coalición debido a la competencia interna (Barreda, 2004; Navia y Rojas, 2008). Muchas veces, las primarias dejan enemistados a los grupos internos, afectando el desempeño del partido en la elección general (Altman, 2012; Agranov, 2012). Los candidatos acumulan cansancio, invierten tiempo y recursos para ganar la primaria,

$4 \quad$ El selectorado es definido como el cuerpo que selecciona al candidato. Este puede estar compuesto por una o muchas personas, así como por el electorado total habilitado en un país (Rahat y Hazan, 2001; Rahat, 2009; Kenig, 2009). 
lo que puede debilitar paulatinamente sus opciones de triunfo (Buquet y Chasquetti, 2008; Carey y Polga-Hecimovich, 2006). Por eso mismo, las primarias deben hacerse con suficiente antelación a la elección general. Incluso, algunos recomiendan no hacerlas. Ejemplo de ello fue Venezuela en 2013. En esa ocasión el presidente Nicolás Maduro evitó que se realizaran primarias municipales en su partido (Partido Socialista Unido de Venezuela, PSUV), advirtiendo que el chavismo podía quedar fragmentado en "pedazos". 5

Las condiciones que favorecen la realización de elecciones primarias han sido ampliamente discutidas por la literatura comparada (Kemahlioglu et al., 2009). Para algunos, es más probable que los partidos se decidan por este tipo de MSC cuando las preferencias de sus líderes son similares a las preferencias de los votantes (Serra, 2008 y 2011). El objetivo de los líderes es legitimar un candidato que, siendo a su juicio mayoritario entre los votantes, requiera de un apoyo electoral adicional. Así, ese candidato mayoritario llegará a la elección general con un piso de votación que podría asegurar su triunfo. Pero también es probable que las primarias se apliquen cuando los partidos tienen candidatos débiles (Adams y Merril, 2008). En estos casos se impulsa una primaria a fin de que ese candidato débil tenga la visibilidad suficiente para transformarse en un candidato competitivo en la elección general. Destacan los ejemplos del PRI en México (Langston, 2009) y el Partido Justicialista y la Unión Cívica Radical en Argentina (De Luca et al. 2002).

\section{Elecciones primarias: participación y elegibilidad}

La participación en las elecciones primarias se puede entender de dos formas. Por un lado se pueden caracterizar las variables que determinan la participación en primarias. Por otro, es posible analizar el efecto que tiene la participación en primarias sobre la participación en la elección general.

Kenney y Rice (1985) estudiaron las variables que determinaron la participación en las elecciones primarias. Demostraron que para las primarias presidenciales en Estados Unidos el gasto en campaña y la cercanía de la elección no estimulaban la participación. Por el contrario, cuando existía un balance partidario -que es la competencia entre dos partidos fuertes- la participación tendía a aumentar. Asimismo, Polsby (1983) y Lengle (1981) argumentaron que quienes votan en las elecciones primarias son los electores más educados, de más alto nivel socioeconómico y más ideologizados. En la misma línea, Buquet y Piñeiro (2011) muestran que en las primarias uruguayas participan mayormente los votantes más educados, de mayor edad y que tienen posiciones ideológicas más extremas. Por tanto es esperable que los precandidatos que se ubican en posiciones más radicales resulten beneficiados por el uso de primarias, lo que también aplica en el estudio de Brady et al. (2007) sobre el congreso estadounidense.

5 América Economía. 2013. Maduro cree que primarias para municipales habrían dejado al chavismo partido en pedazos. Publicado el 16 de agosto de 2013. Revisado el 30 de mayo 2014. Disponible en: http: / / www.americaeconomia. $\mathrm{com} /$ politica-sociedad/politica/maduro-cree-que-primarias-para-municipales-habrian-dejado-al-chavismo-par 
En cuanto al efecto de las primarias sobre la participación, Navia y Rojas (2008), basándose en las primarias presidenciales chilenas de 1993 y 1999, sostienen que la participación electoral en las elecciones primarias tiene un efecto favorable en la participación de las elecciones generales. Algo similar sostiene Brieba (2013) al estudiar el efecto de las primarias municipales de 2012 en Chile sobre la participación electoral en la elección local de ese mismo año. ${ }^{6}$ Lo mismo han constatado Kanthak y Morton (2003) para las elecciones de congresistas en Estados Unidos de 1982, 1986 y 1990. Algo distinto ha señalado McGhee (2014), argumentando que ni el sistema de primarias ni los incentivos para generar más participación electoral -como el registro de votantes el mismo día de la elección- han contribuido a elevar el número de votantes (McGhee, 2014).

Si las elecciones primarias tienen efecto en la participación, resulta indispensable cuestionarse si este tipo de MSC impacta en la elegibilidad de los candidatos escogidos por medio de primarias. La literatura para el caso norteamericano ha mostrado sistemáticamente el efecto negativo que tienen las elecciones primarias en el resultado final de la elección. Utilizando la teoría espacial del voto de Downs (1957), diversos trabajos han mostrado las diferencias entre el votante mediano de las elecciones primarias y el de la elección general. Se argumenta que quienes votan en elecciones primarias son electores más extremos que los votantes que sufragan en las elecciones generales y que esto repercute en el resultado de la elección (Key, 1947; Ranney, 1968; Polsby, 1983; Lengle, 1981; Abramowitz, 1995; Lengle et al., 1995; McCann, 1995). Sin embargo, algunos estudios han constatado que esto no es necesariamente cierto. Geer (1988) demostró que los votantes en las primarias son más moderados que los electores partisanos, por lo que no existiría tal efecto negativo en la elegibilidad. Con esto, Geer (1988) advierte que el universo de votantes en las primarias abiertas -donde votan tanto militantes como no militantes- va más allá de los electores identificados con el partido. Trabajos posteriores han mostrado resultados similares (Gerber y Morton, 1998; Kaufmann et al., 2003; Wuhs, 2008; Mikulska y Scarrow, 2010).

Los estudios de primarias enfocados en para América Latina revelan evidencia igualmente contradictoria. Altman (2012) y Buquet y Piñeiro (2011), en sus respectivos estudios acerca del caso uruguayo, muestran cómo las primarias permiten la elección de candidatos más extremos respecto del votante mediano. Sin embargo, y debido al entramado institucional que regula las elecciones primarias en este país, esto no necesariamente afecta la elegibilidad de los candidatos en las elecciones generales debido a que las primarias son obligatorias y concurrentes para todos los partidos (Buquet y Piñeiro, 2011; Altman, 2012). Otros trabajos sobre primarias en América Latina sugieren evidencia similar. Colomer (2002) argumenta que a mayor nivel de participación en las primarias es más probable que sean elegidos candidatos extremos. Naturalmente esto genera una "distancia entre el ganador de la primaria y la preferencia del votante mediano en el conjunto del electorado" (Colomer, 2002: 3). Bruhn (2010), considerando México como caso de estudio, sostiene que el uso de primarias trae como efecto un deterioro de la elegibilidad. Esto se debería, en gran parte, al déficit organizacional de los partidos 
y a las bajas barreras de entrada para la proliferación de candidatos. Por lo tanto, las primarias, en lugar de fortalecer a los candidatos ganadores, terminan fracturando el partido y gatillando un conflicto imposible de subsanar al momento de la elección general. Los adherentes del candidato perdedor suelen desmovilizarse, haciendo aún más difícil la campaña para el ganador que, por esta misma falta de apoyo, está a merced de las críticas del partido oponente.

\section{LAS PRIMARIAS MUNICIPALES DE LA CONCERTACIÓN}

La Concertación es la coalición política chilena con mayor experiencia en elecciones primarias. Para el año 2012 la coalición de centro-izquierda ya había realizado tres primarias presidenciales y una para escoger alcaldes. La primera elección primaria fue en 1993 cuando Eduardo Frei (PDC) se impuso a Ricardo Lagos (PPD-PS) con 62,9\% y $37,1 \%$ de los votos respectivamente (Auth, 2005; Navarrete, 2005). Este mecanismo de selección se replicó en 1999 para la elección del candidato presidencial, donde compitieron Andrés Zaldívar (PDC) y Ricardo Lagos (PPD-PS). Este último ganó con un 71,4\% (Auth, 2005). En 2009 nuevamente la Concertación escogió a su presidenciable por medio de una primaria. La diferencia es que dicho proceso se implementó solo en dos regiones (la VI de O'Higgins y la VII del Maule), triunfando Eduardo Frei (PDC) con 64,9\% de apoyo por sobre el senador José Antonio Gómez del Partido Radical Socialdemócrata (PRSD).

En las primarias que organizó la Concertación para elegir sus candidatos a los comicios municipales de octubre de 2012 participaron 313.817 votantes en 141 comunas. ${ }^{7}$ Hubo 336 candidatos. En promedio, compitieron 2,38 candidatos por comuna. En más del $70 \%$ de las comunas hubo dos candidatos, mientras que en casi el $20 \%$ compitieron tres candidatos. La participación fue mayor en las comunas pequeñas que en las comunas grandes. Por ejemplo, y considerando como base de comparación los votos válidamente emitidos de la última elección de diputados, para la primaria participó más del 40\% de esos votantes en Sagrada Familia (VII Región, con 17.764 habitantes según la proyección para 2012 del censo de 2002), mientras que en San Bernardo solo lo hizo el 2,15\% (Región Metropolitana con 277.225 habitantes).

\section{¿Qué comunas fueron a primarias?}

La Concertación hizo primarias en 58 de las 147 comunas que obtuvo en 2008 (39,5\%). ¿Lo hizo en las comunas donde era más fuerte electoralmente? Para probar esto, construimos un modelo probit (ver Tabla 1). La variable dependiente es dicotómica, donde 1 indica aquellas comunas en las que hubo primarias y 0 en las que no hubo. Las variables independientes corresponden al porcentaje de votos de la Concertación en 2008 (elección de concejales),

7 Las elecciones primarias municipales de la Concertación se realizaron el 1 de abril. A este resultado se sumó la elección primaria realizada en Punta Arenas, la que se efectuó el 15 de abril (Bustamante, 2012).

8 Esta cifra crece a 148 si sumamos Antofagasta. Acá la entonces alcaldesa Marcela Hernando decidió participar de las primarias de la Concertación. 
número de electores, índice de desarrollo humano, una variable dummy que distingue las comunas gobernadas por la Concertación y por el resto de los partidos, y una variable que señala el número de períodos del incumbente en el cargo. Construimos tres modelos. El primero incluye el total de comunas. La sumatoria de comunas es de 336 y no de 345 (que es el total nacional), debido a que la Concertación no compitió con candidatos en la elección de concejales (que es una de nuestras variables independientes) en 9 comunas. El segundo modelo considera las 148 comunas que ganó la Concertación en 2008. El tercer modelo, en tanto, agrupa las 289 comunas donde el alcalde en ejercicio decidió repostular al cargo. Nuevamente, la sumatoria del modelo arroja un valor inferior (282) debido a la ausencia de la Concertación en algunas comunas para la elección de concejales de 2008.

Los tres modelos muestran, sistemáticamente, que la Concertación realizó primarias en comunas donde era poderosa y en comunas donde era débil. Al mismo tiempo, la probabilidad de primarias aumentaba en las comunas más grandes. Se realizaron primarias, por ejemplo, en Valparaíso, Maipú, y La Florida, donde el número de electores sobrepasaba los 160 mil. Pero también se hicieron primarias en comunas pequeñas como Palena y San Gregorio, con aproximadamente 1.200 electores.

El resto de las variables son escasamente significativas. En el modelo 3, no obstante, el número de períodos de alcalde que repostula incide en la probabilidad de realizar primarias. Es cierto que el dato de repostulación lo conocemos con posterioridad a la primaria, pero también es justo reconocer (como sostienen nuestros entrevistados) que los partidos manejan esta información con suficiente antelación. En el caso de la Concertación, estaba muy claro qué alcaldes repostularían y bajo qué condiciones. Es decir, si serían sometidos a primarias o si serían nominados directamente. Por cierto, les era más difícil predecir qué alcaldes de la Alianza buscarían la reelección, pero en términos generales contaban con información confiable.

Comprensiblemente, los partidos son reacios a hacer primarias en comunas con alcaldes consolidados. Al mismo tiempo, habrá menos desafiantes disponibles para competir frente a ese alcalde. La probabilidad de derrota es alta y, en consecuencia, lo más razonable sería no dar la pelea. De las 148 comunas que la Concertación obtuvo en 2008 (se suma Antofagasta por las razones mencionadas), las 58 comunas en que hubo primarias tenían alcaldes que, en promedio, llevaban 2,19 períodos en el cargo, mientras que las comunas de la Concertación que no fueron llevadas a primarias tenían un promedio de 2,53 períodos. ${ }^{9}$ Las diferencias son mínimas, pero indican que, en efecto, la probabilidad de realizar primarias decrece cuando existen alcaldes con un mayor número de períodos en el cargo. Si calculamos el peso de cada comuna en función de los votos válidamente emitidos en la elección de alcaldes 2008, las diferencias son mucho más abultadas. En las comunas con primarias los alcaldes en ejercicio promedian 1,99 períodos, mientras que las comunas sin primarias promedian 2,93 períodos. Esto se debe a que, por ejemplo,

9 En 1992 hubo alcaldes que gobernaron 2 años. Es decir, la mitad del período. Para efectos de conteo, esos dos años se han codificado como un período. Tales alcaldes son Carlos Gómez en Queilén, Rubén Cárdenas en Calbuco (gobernó los dos primeros años), Lorenzo Torres en Paihuano, Omar Alvarado en San Pablo y Sandra Martínez en San Pedro de Atacama (los tres alcaldes gobernaron los dos últimos años). 
el PDC no llevó a primarias comunas grandes como Macul, La Granja, San Fernando y Quillota. Lo propio hizo el PS con Pudahuel y El Bosque, y el PPD con San Joaquín.

Casi en la mitad de las comunas con alcaldes concertacionistas de un período se realizaron primarias (18 de 40), mientras que en las comunas con alcaldes que gobernaban desde 1992 (5 periodos) se efectuaron primarias solo en 2 de 16 comunas (Taltal y Queilén, ver Tabla 2). Con los datos del modelo 3 calculamos la probabilidad de que haya una elección primaria en función del número de períodos del alcalde que busca la repostulación. Excluimos del análisis las 56 comunas con alcaldes que decidieron no repostular. De todos modos, si las incluyéramos en el análisis, el resultado no variaría sustantivamente. El Gráfico 1 muestra que la probabilidad de que se haga una primaria es de 0,41 en comunas con alcaldes de un período y de 0,25 en alcaldes con cinco períodos. Si se considera solo las comunas de la Concertación, estos valores varían marginalmente.

En consecuencia, no tenemos evidencia de que la Concertación haya hecho primarias en las comunas que más la favorecían electoralmente. Lo que sí es cierto es que se evitaron primarias en comunas con alcaldes que llevaban 4 o 5 períodos en el cargo y que tenían clara intención de repostular.

Tabla 1. Perfil de las comunas donde la Concertación hizo primarias (modelo probit)

\begin{tabular}{lccc}
\hline & $\begin{array}{c}\text { Modelo } 1 \\
\text { Total }\end{array}$ & $\begin{array}{c}\text { Modelo 2 } \\
\text { Comunas de la } \\
\text { Concertación }\end{array}$ & $\begin{array}{c}\text { Modelo 3 } \\
\text { Comunas con } \\
\text { incumbente }\end{array}$ \\
\hline & $\begin{array}{c}\text { 1=Comunas con } \\
\text { primarias/0=Comunas } \\
\text { sin primarias }\end{array}$ & $\begin{array}{c}1=\text { Comunas con } \\
\text { primarias/0=Comunas } \\
\text { sin primarias }\end{array}$ & $\begin{array}{c}1=\text { Comunas con } \\
\text { primarias/0=Comunas } \\
\text { sin primarias }\end{array}$ \\
\hline $\begin{array}{l}\text { Porcentaje de votos Concertación } \\
\text { (concejales 2008) }\end{array}$ & 0.00750 & -0.00548 & $2.22 \mathrm{e}-05$ \\
Número de electores por comuna & $(0.00633)$ & $(0.0100)$ & $(0.00536)$ \\
Índice de desarrollo humano & $2.74 \mathrm{e}-06^{* *}$ & $8.89 \mathrm{e}-06^{* * *}$ & $3.25 \mathrm{e}-06^{*}$ \\
comunal & $(1.32 \mathrm{e}-06)$ & $(2.78 \mathrm{e}-06)$ & $(1.68 \mathrm{e}-06)$ \\
Militancia alcalde & -1.014 & -1.984 & -1.070 \\
(0=Otros/1=Concertación) & $(0.871)$ & $(1.407)$ & $2.22 \mathrm{e}-05$ \\
Número de períodos en el cargo & -0.277 & & \\
del alcalde & $(0.193)$ & & $-0.116^{*}$ \\
Constante & & -0.141 & $(0.0676)$ \\
Observaciones & & $(0.0893)$ & 0.494 \\
\hline
\end{tabular}

Error estándar entre paréntesis

${ }^{* * *} \mathrm{p}<0.01,{ }^{* *} \mathrm{p}<0.05,{ }^{*} \mathrm{p}<0.1$

Fuente: Elaboración propia con datos de www.primariasmunicipales2012.cl, www.elecciones.gov. cl, www.servel.cl 
Tabla 2. Selección de las comunas con primarias según el número de períodos del incumbente

\begin{tabular}{cccr}
\hline Número de períodos del incumbente & Sin primarias & Con primarias & Total \\
\hline 1 & 22 & 18 & 40 \\
2 & 32 & 24 & 56 \\
3 & 16 & 5 & 21 \\
4 & 6 & 9 & 15 \\
5 & 14 & 2 & 16 \\
Total & 90 & 58 & 148 \\
\hline
\end{tabular}

Fuente: Elaboración propia con datos de www.primariasmunicipales2012.cl y www.elecciones.gov.cl

Gráfico 1. Probabilidad de realización de primarias según en número de período del alcalde

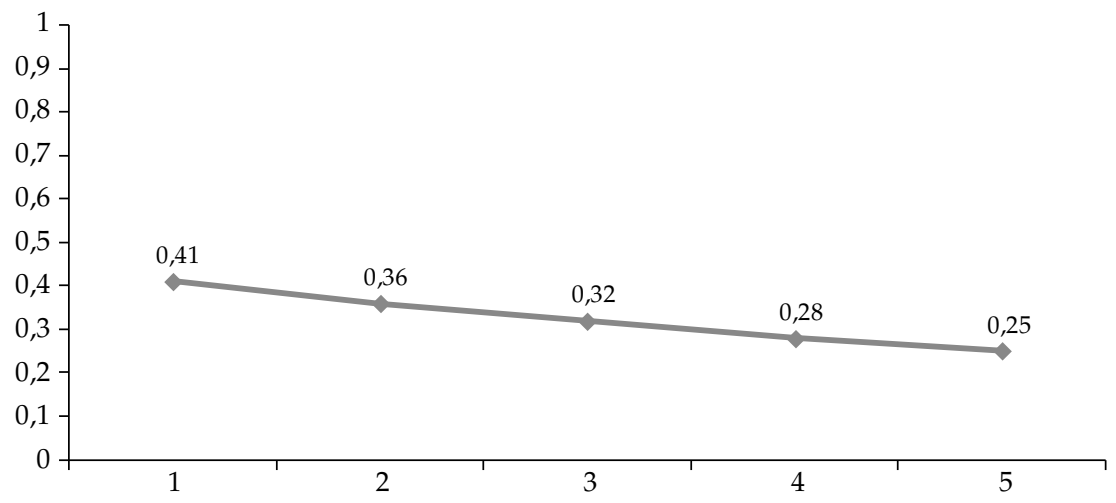

Fuente: Elaboración propia con datos de www.primariasmunicipales2012.cl y www.elecciones.gov.cl

\section{Participación, tamaño e ingresos}

El Gráfico 2 muestra la correlación entre el número de votantes por comuna y el porcentaje de participación en las primarias. La correlación es negativa, indicando que a mayor volumen poblacional de la comuna se registró menos participación. Para medir el tamaño poblacional de cada comuna utilizamos tanto el número de votos válidamente emitidos en las elecciones de diputados 2009 como el número de votos emitidos en la primaria. Como generalmente las comunas pequeñas tienen mayores niveles de pobreza, resulta esperable, tal como muestra el Gráfico 3, que exista una relación inversa con el Índice de Desarrollo Humano comunal. Es decir, que a mayor riqueza, menor participación. Como mostramos más adelante, esta relación se sostiene al analizar la participación electoral en la elección municipal de 2012. 
Gráfico 2. Porcentaje de votantes en las elecciones primarias en función del número de votos válidamente emitidos en la elección de diputados 2009 y de los votos emitidos en la primaria 2012 por comuna
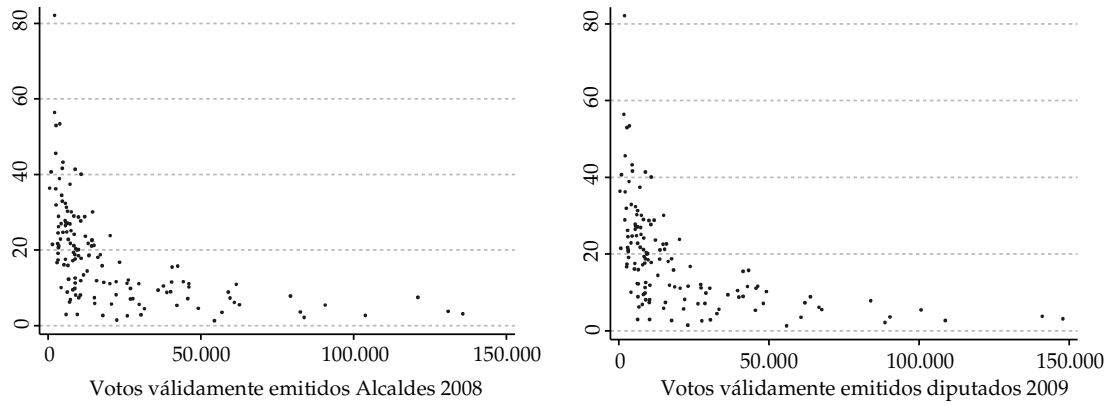

Fuente: Elaboración propia con datos de www.primariasmunicipales2012.cl

Gráfico 3. Índice de Desarrollo Humano por comuna y participación electoral primarias 2012

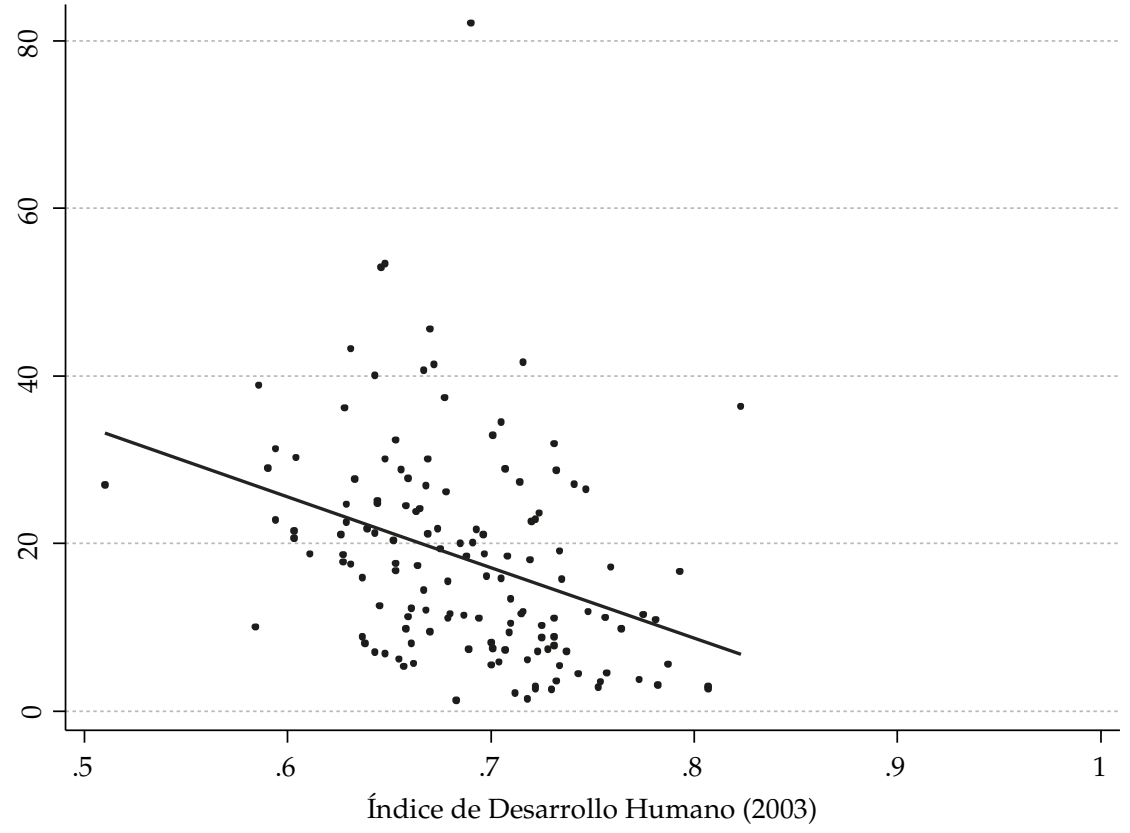

Fuente: Elaboración propia con datos de www.primariasmunicipales2012.cl

\section{Participación e incumbencia}

Teóricamente, la participación electoral debiese ser más alta en aquellas comunas donde había alcaldes en ejercicio que compitieron en la primaria. Es decir, que eran incumbentes. Sostenemos que los incumbentes, como conocen la comuna y han desarrollado su actividad por al menos cuatro años, tienen mayor capacidad para movilizar electores. Esto genera 
una ventaja muy difícil de superar para los desafiantes (Jacobson, 1981; Gelman y King, 1990; Moon, 2006; Morgenstern y Siavelis, 2008). No obstante, afirmamos que si bien en estas comunas hay más participación en comparación a aquellas donde no compite un incumbente, esa participación va disminuyendo en la medida en que los incumbentes obtienen mayor porcentaje de votación.

Es decir, la presencia de incumbentes poderosos puede deprimir la competencia y, junto con ello, la participación. Sabemos que la relación entre competencia y participación es endógena, pero pensamos que si bien el índice de competencia se conoce después de que la gente ya ha participado, el ambiente de la campaña bien puede ser un buen proxy de competencia (Johnston et al., 2007; Indridason, 2008; Simonovits, 2012). Esta información es mucho más clara cuando compite un incumbente que es conocido en la comuna.

Particularmente en elecciones primarias tanto los electores como el candidato desafiante conocen los atributos del incumbente. En tal sentido, bien podrían anticiparse el resultado considerando la capacidad movilizadora y de recursos del alcalde que aspira a la reelección. Cuando este incumbente se impone por amplio margen, lo más probable es que la participación haya quedado recluida a la movilización que efectuó ese incumbente frente a un desafiante débil. En cambio, una derrota del incumbente es eventualmente acompañada de una alta participación. En este escenario, tanto el incumbente como el desafiante movilizan electores.

A juicio de uno de nuestros entrevistados, los incumbentes no solo aprovechan las ventajas propias de su cargo, sino que también generan estrategias de amedrentamiento frente al desafiante. Al momento de enfrentar la elección, el incumbente moviliza de manera masiva a su núcleo de votantes. La mayor disposición de recursos hace que, muchas veces, el desafiante decida abandonar la competencia antes de la elección. En efecto, la participación electoral será reducida, pues estará compuesta casi exclusivamente por los electores del incumbente. Así, las primarias se transforman más en un trámite electoral que un evento realmente competitivo. Con un resultado favorable, el incumbente no solo se sentirá depositario del respaldo popular, sino que también en una posición de jerarquía incluso frente a los dirigentes de su partido. Esto no hace más que retratar la personalización de la política, que es reconocida incluso por los propios impulsores de este MSC: "Es muy difícil remover a un alcalde que busca la reelección. Pero más difícil es hacerlo cuando gana una primaria. Su argumento es muy sencillo: gané en la elección pasada, gané la elección primaria. ¿Por qué me van sacar del cargo? En un escenario así, los dirigentes de los partidos no pueden hacer nada. Es la persona (candidato ganador) la que manda. A nosotros no nos queda otra que acatar" (Informante A).

Lo anterior queda de manifiesto en el Gráfico 4 . Al observar los datos que corresponden a comunas donde participaron o no participaron incumbentes, se advierte que a mayor porcentaje de votos a favor de los incumbentes, menor es la participación electoral. En el caso de las comunas sin incumbentes, la participación no varía en función del porcentaje de votos del ganador. Naturalmente, el porcentaje de votos de los incumbentes está mediado no solo por la calidad del desafiante, sino que también por el número de desafiantes. De los 39 incumbentes en competencia, 35 enfrentaron a un solo desafiante, mientras 
que 4 incumbentes se enfrentaron a dos desafiantes. Por ende, la tendencia de los datos no está significativamente mediada por el número de candidatos en competencia. En la amplia mayoría de las comunas donde compitió un incumbente, también lo hizo un solo desafiante.

Para reforzar este argumento construimos un modelo de regresión lineal que intenta explicar las variaciones de la participación electoral. Creemos, de acuerdo a la literatura citada, que esa participación obedece no solo al tamaño de la comuna (número de votantes), sino que también a la presencia de incumbentes y su desempeño electoral. Como suponemos que la participación cae en la medida en que los incumbentes ganan por mayor margen, construimos un término de interacción entre incumbente y su porcentaje de votación. Los resultados del modelo aparecen en la Tabla 3. El modelo está ponderado según tamaño comunal medido por el número de electores. Para mostrar de manera más clara estos resultados construimos una simulación estadística con el paquete zelig del software R y cuya representación está en el Gráfico 5. La línea negra corresponde a las comunas donde compiten los incumbentes. Acá se muestra que en la medida en que aumenta la votación de los incumbentes, cae la participación electoral. En tanto, la línea gris corresponde a las comunas donde no participan incumbentes. Como se observa, el nivel de participación en estas comunas es más bajo, pero el rendimiento de los ganadores (porcentaje de votos) no va asociado a cambios en la participación.

El Gráfico, además, muestra que las diferencias más marcadas entre ambos grupos (comunas con y sin participación de incumbentes) se producen cuando el incumbente obtiene en torno al 50\% y 55\% de los votos. Es decir, comunas competitivas. Acá la participación es sustancialmente más alta en comparación a comunas donde no participaron incumbentes. En cambio, cuando ese incumbente obtuvo el 70\% o más, la participación cayó significativamente, llegando a porcentajes similares al de comunas donde no participó un candidato incumbente.

Dadas estas características, otro de nuestros informantes sostiene que los incumbentes solo ven en las primarias una simple estrategia de legitimación electoral que tiene como objetivo no solo ganar la elección general, sino que también construir una especie de blindaje frente a las directivas partidarias. "Esto de las primarias no hace más que favorecer a los caudillos. Cuando ellos ganan la primaria, nosotros no tenemos ningún argumento para cambiar de candidato aunque su gestión como alcalde haya sido mala. En muchas comunas la gente tiene mala opinión de ese alcalde pero no sale a votar. Entonces, estos 'gallos' (los alcaldes) mueven gente el día de la elección y ganan. Pero después pueden perder en la elección general y somos los dirigentes los que tenemos que poner la cara. Hay que tener más cuidado con esto de entregar el poder de decisión a la gente. Hay que dar más poder a los partidos para decidir estas cosas" (Informante B). Por último, incluso en escenarios de primarias competitivas el resultado final podría alejarse del óptimo. Debido a que estas primarias no fueron reguladas por una institución independiente como el Servicio Electoral (SERVEL), un resultado estrecho podía animar acusaciones de fraude. Para evitar este tipo de conflictos los partidos decidieron realizar la primaria con bastante anticipación. "Luego de una elección primaria estrecha, cuesta 
sanar las heridas. Al perdedor le cuesta reconocer el resultado y no vuelca su apoyo de manera entusiasta hacia el ganador. Por eso mismo las primarias deben hacerse con bastante anticipación" (Informante C).

Gráfico 4. Porcentaje de votos del candidato ganador y participación electoral por comuna y según ausencia o presencia de candidatos incumbentes

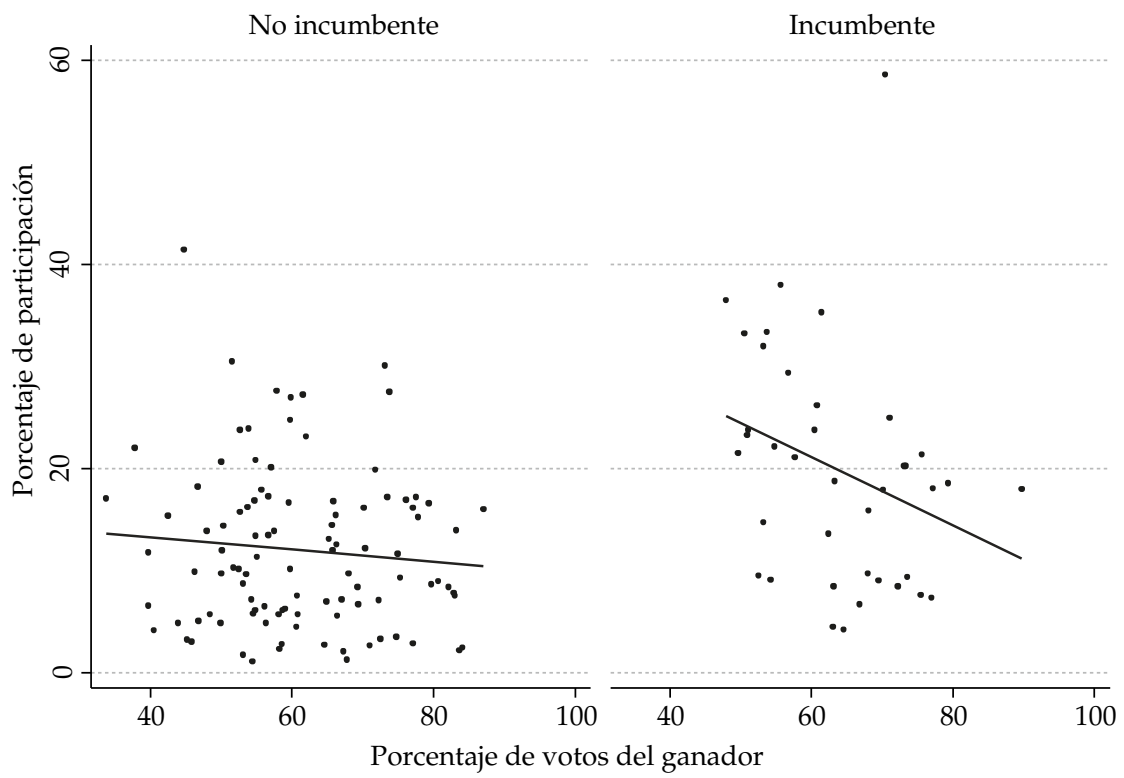

Fuente: Elaboración propia con datos de www.primariasmunicipales2012.cl

Tabla 3. Modelo de Mínimos Cuadrados Ponderados (MCP). La variable dependiente es el porcentaje de participación en la primaria

\begin{tabular}{lc}
\hline \multicolumn{1}{c}{ Variables } & Participación Primarias 2012 \\
\hline Porcentaje de votos del ganador & 0.0308 \\
& $(0.0533)$ \\
Incumbente (0=No incumbente $/ 1=$ Incumbente) & $20.81^{* *}$ \\
Porcentaje de votos del ganador*Incumbente & $(8.822)$ \\
& $-0.250^{*}$ \\
Constante & $(0.135)$ \\
Observaciones & 5.207 \\
R Cuadrado & $(3.239)$ \\
\hline
\end{tabular}

Fuente: Elaboración propia con datos de www.primariasmunicipales2012.cl 
Gráfico 5. Simulación estadística. El efecto del desempeño electoral y la incumbencia sobre la participación electoral*

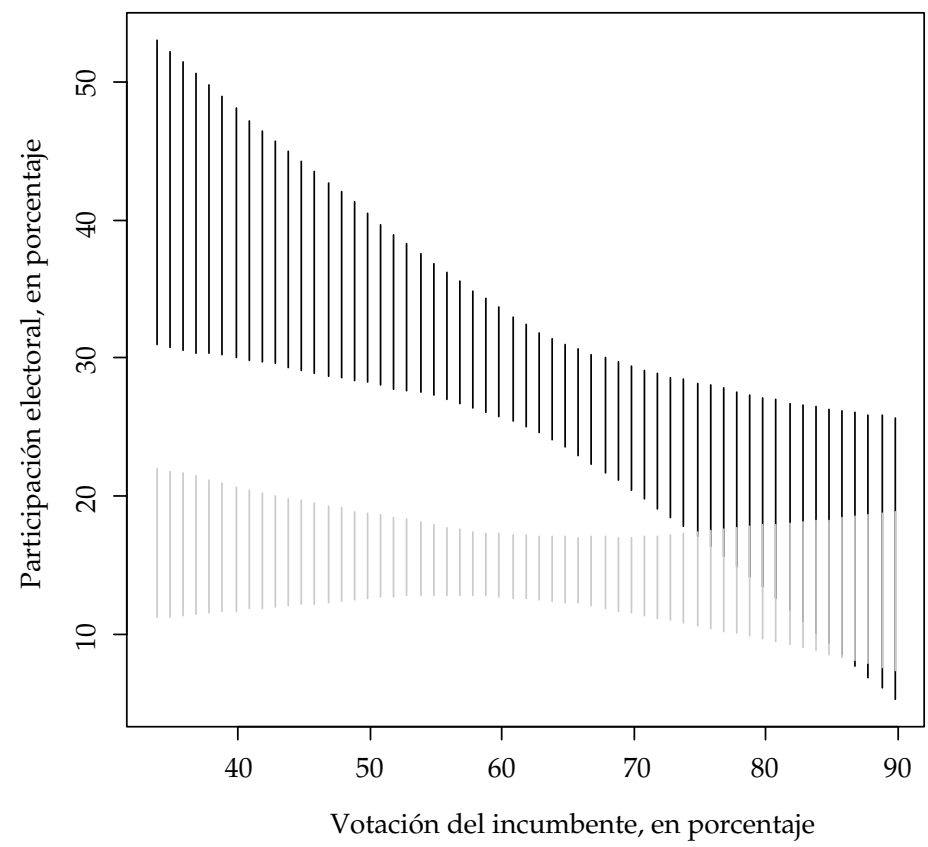

Fuente: Elaboración propia con datos de www.primariasmunicipales2012.cl

* La línea negra corresponde a comunas donde compite un incumbente. La línea gris corresponde a comunas donde no compite un incumbente.

\section{IV. ¿QUÉ EFECTO TUVO LA PARTICIPACIÓN EN LAS PRIMARIAS SOBRE LA PARTICIPACIÓN EN LA ELECCIÓN MUNICIPAL?}

Según Brieba (2013) la participación electoral fue mayor en las comunas con primarias y especialmente en las comunas pequeñas. Nuestros datos arrojan una interpretación diferente. Al aislar las comunas donde hubo primarias (141), es cierto que existe una correlación directa entre la participación en primarias de cada comuna y la participación en la elección municipal de octubre de 2012. Vale decir, a mayor participación electoral en las primarias, mayor participación en las municipales. Esto podría llevar a pensar que, en efecto, las primarias favorecen la participación electoral. El Gráfico 6 así lo muestra. En el eje vertical está la diferencia porcentual de participación comparando las municipales de 2008 y 2012. En el eje horizontal, en tanto, está el porcentaje de participación en las primarias. Como la relación es directa, entonces a mayor participación en las primarias, mayor participación en la municipal 2012 respecto de la municipal 2008. Es evidente que el diferencial de participación comparando 2008 y 2012 es negativo. Esto, porque la participación en 2012 fue sustantivamente inferior a 2008. De todos modos, el Gráfico 
nos muestra que en aquellas comunas donde la participación en primarias fue mayor, la caída de la participación en 2012 respecto de 2008 fue de menor magnitud.

Sin embargo, esta inferencia peca de un sesgo en la selección de casos y solo obedece a una ilusión óptica. La gráfica excluye, naturalmente, a las comunas donde no se hicieron primarias. Por tanto, la pregunta central sigue sin responderse: ¿hay diferencias estadísticamente significativas en la participación electoral entre comunas donde hubo y no hubo primarias? Para responder esta pregunta es necesario no solo comparar el resultado de la participación en comunas con y sin primarias, sino que, más importante aún, generar un modelo capaz de controlar por otras variables. De acuerdo con los datos que hemos revisado, claramente una de las variables que incide sobre la participación electoral es el tamaño de la comuna. Es decir, su número de electores. Más arriba constatamos que la participación es más alta en las comunas pequeñas en comparación con las comunas grandes al menos para el caso de las primarias. En función de esto, es esperable que la relación también se sostenga para las elecciones municipales.

El Gráfico 7 muestra la relación entre el cambio porcentual de la participación electoral entre 2008 y 2012, y el tamaño comunal. Hemos segmentado los datos según comunas donde hubo y no hubo primarias. En efecto, la relación entre participación y tamaño comunal es inversa. Vale decir, a mayor tamaño, menos participación. Esto es así tanto para las comunas que tuvieron primarias como para las que no tuvieron primarias, lo que nos lleva a pensar, preliminarmente, que ambos grupos se comportan de manera similar. A esto debemos agregar que la participación promedio en las comunas con primarias fue de $42,56 \%$, mientras que la participación promedio en las comunas sin primarias fue de 43,78\%. Es decir, casi idénticas.

Por tanto, no existen diferencias entre comunas con y sin primarias de acuerdo con la participación electoral, a lo que se suma el hecho de que el comportamiento de las comunas en función de su número de electores es casi idéntico para ambos grupos. Para ordenar estas interpretaciones construimos un modelo de regresión lineal. La variable dependiente es el porcentaje de cambio en la participación entre 2008 y 2012. Las variables independientes son las siguientes:

a) Primarias. Acá codificamos con el valor de 1 a las comunas donde hubo primarias y con 0 a las comunas donde no hubo primarias. Si el coeficiente es significativo, nos señalará que hay diferencias en la participación para ambos grupos de comunas. De acuerdo con la evidencia descriptiva, nuestra hipótesis es que no existen diferencias estadísticamente significativas entre los grupos.

b) Tamaño. Corresponde al número de electores de cada comuna. Debido a la aplicación del régimen electoral de inscripción automática y voto voluntario, el padrón creció de 8,1 millones en 2008 a 13,4 en 2012. De acuerdo con la evidencia descriptiva, nuestra hipótesis es que a mayor tamaño, menor participación.

c) Incumbencia. Codificamos con el valor de 1 a las comunas donde hubo un candidato a alcalde incumbente y con 0 a las comunas donde no hubo candidatos a alcalde 
incumbentes. Esta variable solo cumple la función de control. Si bien la incumbencia es una variable decisiva para explicar la participación en una elección primaria, no necesariamente lo será para una elección municipal.

d) Pobreza. Teóricamente, la participación debiese ser menor en las comunas pobres en comparación a las comunas ricas, más aún con el régimen de voto voluntario (Lijphart, 1997).

e) Competencia. Teóricamente, a mayor competencia (medida como la diferencia entre el ganador y el perdedor de la elección a alcalde), mayor participación (Jackman, 1987; Jackman y Miller, 1995).

f) Pobreza/Competencia. Incluimos un término de interacción entre participación y competencia. Nuestra hipótesis es que en las comunas ricas y poco competitivas, la participación electoral es superior que en comunas pobres y poco competitivas.

Los resultados del modelo cumplen con las hipótesis esperadas (ver Tabla 4). La más relevante para la pregunta que nos formulamos en este artículo corresponde a las diferencias entre comunas con y sin primarias. Confirmando el análisis descriptivo, las comunas con y sin primarias no presentan diferencias estadísticamente significativas en términos de participación electoral. Entre 2008 y 2012 el cambio de la participación es prácticamente idéntico entre ambos grupos. Esto incluso es válido tanto para las comunas con $70 \mathrm{mil} \mathrm{y}$ más electores como para las comunas con menos de 70 mil electores. Esta cifra límite la hemos establecido porque las comunas con más de 70 mil electores eligen 8 concejales.

El resto de las hipótesis aplica parcialmente dependiendo del tamaño de cada comuna. Es decir, si pertenece al grupo de 70 mil electores o más, o menos de 70 mil electores. Así por ejemplo, para este último grupo de comunas la única variable significativa es el número de electores. Mientras tanto, para el grupo de 70 mil o más electores no solo el tamaño de la comuna es significativo, sino que también la pobreza y la competencia. En especial destaca la significancia del término de interacción. Mediante ese coeficiente deducimos que, en efecto, la participación en las comunas ricas y poco competitivas es mayor que en las comunas pobres y poco competitivas (ver Contreras, Joignant y Morales, 2014).

En síntesis, y como señalamos más arriba, la participación en las comunas donde la Concertación hizo primarias es prácticamente idéntica a la participación en las comunas donde no hubo primarias. Por lo tanto, y tal como afirmó McGhee (2014), el hecho de que haya habido primarias es irrelevante para explicar la participación electoral en las municipales 2012. Esto, y contrario a lo que señala Brieba (2013), se da tanto para comunas pequeñas como para comunas grandes. 
Gráfico 6. Correlación entre el porcentaje de participación en las elecciones primarias y el cambio porcentual de la participación entre las municipales 2008 y 2012

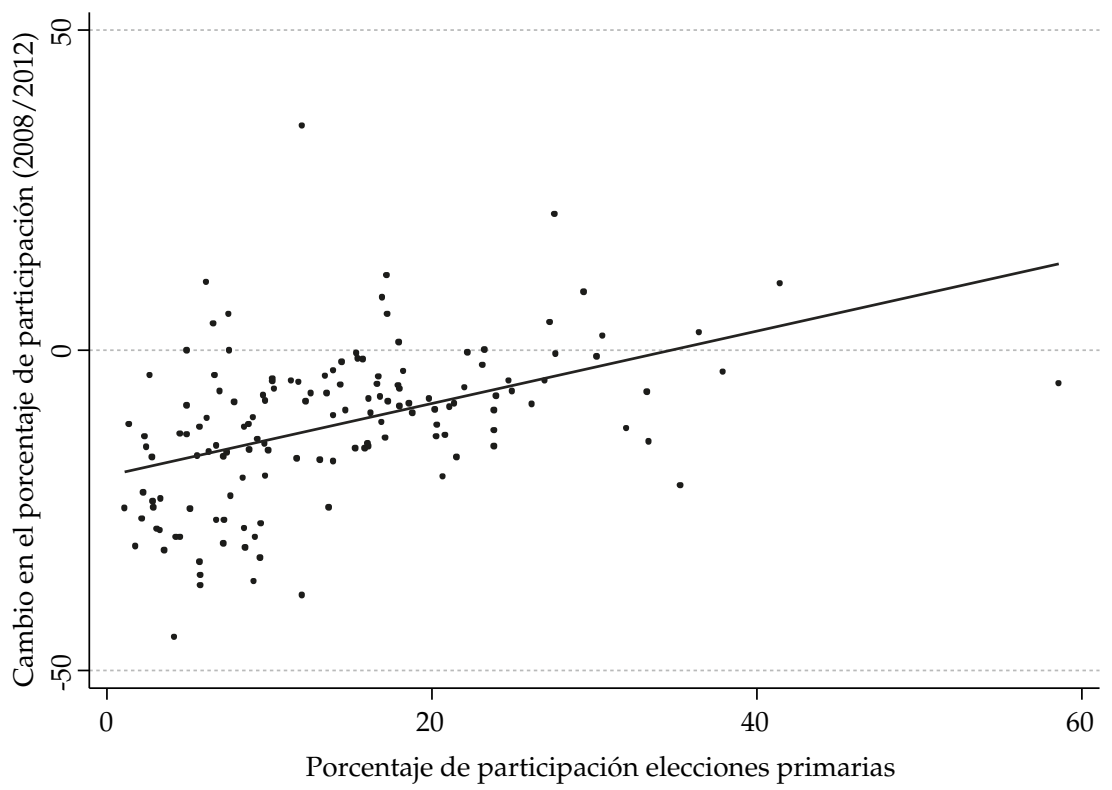

Fuente: Elaboración propia con datos de www.servel.cl y www.primariasmunicipales2012.cl

Gráfico 7. Correlación entre el tamaño electoral de cada comuna y el cambio porcentual de la participación entre las municipales 2008 y 2012 comparando comunas con y sin primarias

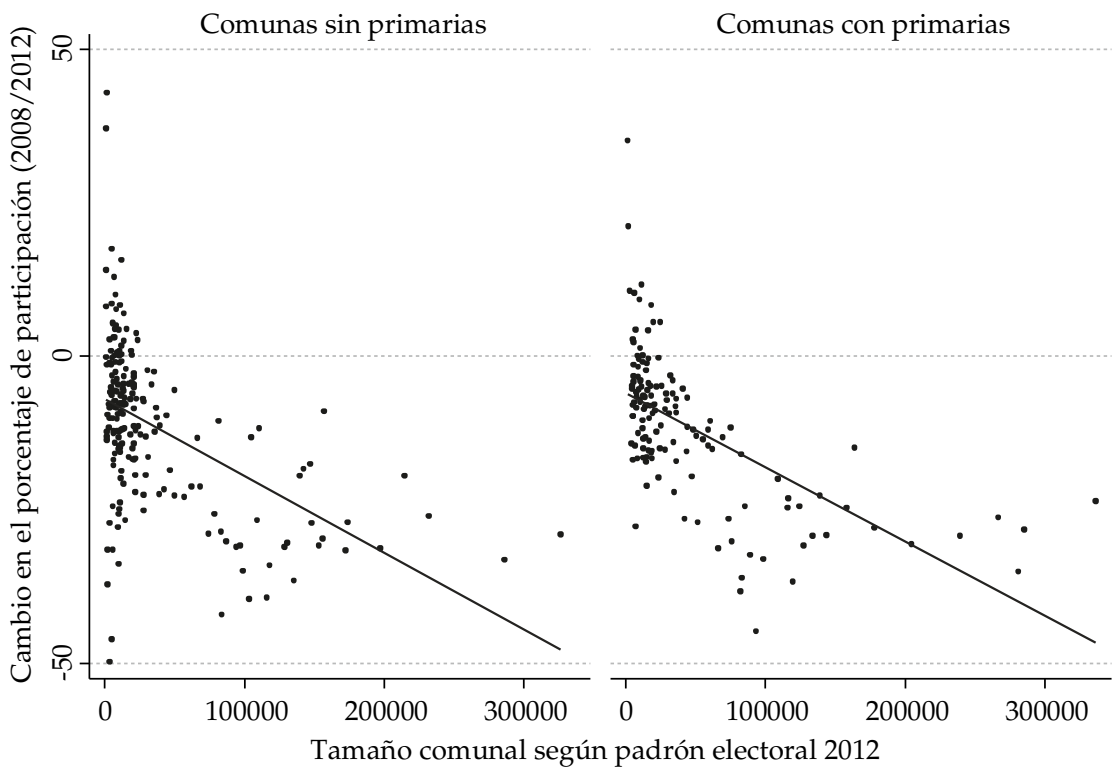

Fuente: Elaboración propia con datos de www.servel.cl y www.primariasmunicipales2012.cl 
Tabla 4. Modelo de regresión lineal. La variable dependiente es el porcentaje de cambio de la participación electoral entre 2008 y 2012

\begin{tabular}{lccc}
\hline & $\begin{array}{c}\text { Comunas con } 70 \text { mil } \\
\text { habitantes y más }\end{array}$ & $\begin{array}{c}\text { Comunas con menos } \\
\text { de } 70 \text { mil habitantes }\end{array}$ & Total \\
\hline Primarias (1=Sí, 0=No) & -1.968 & 1.676 & 0.587 \\
Tamaño del padrón & $(1.04)$ & $(1.28)$ & $(0.49)$ \\
& 0.000 & -0.000 & -0.000 \\
Compite incumbente (1=Sí, 0=No) & $(0.48)$ & $(5.16)^{* *}$ & $(11.22)^{* *}$ \\
Pobreza 2011 & 3.957 & -1.991 & -0.712 \\
& $(1.91)$ & $(1.09)$ & $(0.44)$ \\
Competencia & 0.564 & 0.050 & 0.073 \\
& $(2.75)^{* *}$ & $(0.42)$ & $(0.66)$ \\
Pobreza/Competencia & 0.048 & -0.126 & -0.149 \\
& $(0.44)$ & $(1.26)$ & $(1.74)$ \\
Constante & -0.016 & 0.003 & 0.002 \\
Observaciones & $(2.30)^{*}$ & $(0.66)$ & $(0.33)$ \\
R Cuadrado & -34.471 & -2.789 & -5.450 \\
\hline
\end{tabular}

Fuente: Elaboración propia con datos de www.servel.cl y www.ine.cl

\section{V. ¿QUÉ EFECTO TUVIERON LAS PRIMARIAS SOBRE LA ELEGIBILIDAD DE LOS CANDIDATOS?}

\section{En este apartado evaluamos dos hipótesis:}

a) Las primarias tienen un efecto positivo sobre la elegibilidad de los candidatos. Es más probable que un desafiante gane en la elección general siempre y cuando haya competido previamente en una primaria. Los incumbentes derrotados, en tanto, tienen como característica el hecho de no haber competido en primarias. Más arriba mencionamos la discusión respecto del efecto de las primarias sobre la elegibilidad de los candidatos. Sin perjuicio de que exista un debate acerca del efecto positivo ("bono por primarias") o negativo (desgaste del candidato), en este caso la evidencia apunta en la primera dirección (Rahat y Hazan, 2001; Carey y Polga-Hecimovich, 2006; Serra, 2011).

b) Las variaciones en la participación electoral (2008/2012) son irrelevantes para explicar el resultado de los candidatos incumbentes, pero muy significativas para explicar los resultados de los candidatos desafiantes. A mayor participación, mayor probabilidad de que el candidato desafiante sea derrotado. A menor participación, en tanto, mayor probabilidad de que el desafiante triunfe. No existe un consenso amplio en la literatura sobre la relación entre participación y éxito de los incumbentes. Es posible que un incumbente bien evaluado sea apoyado masivamente el día de la elección, generando así un incremento en la participación. Pero también es probable 
que se produzca lo contrario en caso de enfrentar a un desafiante débil. Igual cosa sucede con incumbentes mal evaluados. Los votantes podrían salir a sufragar para derrotar al incumbente o quedarse en casa si perciben que ese incumbente será elegido a todo evento (ver Grofman et al., 1995; Keele, 2007; Trounstine, 2014).

La Tabla 5 clasifica el desempeño de los candidatos de la Concertación según los criterios de incumbente/desafiante y si fue nominado mediante primarias/no primarias. A grandes rasgos, se advierte que tanto para incumbentes como para desafiantes, el hecho de realizar primarias tiene un efecto positivo en la elegibilidad. De los 32 incumbentes que compitieron en primarias, 23 fueron escogidos alcaldes $(71,8 \%)$. Por su parte, de los 88 restantes que no se sometieron al proceso de primarias, 57 lograron ganar en la elección general de alcaldes (64,8\%). Para los candidatos desafiantes se mantiene el mismo patrón. De los 110 que compitieron en primarias, 54 fueron electos alcaldes $(49,1 \%)$. Mientras que de los 102 desafiantes que no compitieron en primarias, solo 32 lograron ser escogidos alcaldes (31,4\%). En otras palabras, tanto los incumbentes como los desafiantes que participaron en primarias tuvieron una probabilidad de éxito mayor que quienes no se sometieron a este proceso de selección.

Tabla 5. Número de incumbentes y desafiantes ganadores y perdedores en comunas con y sin primarias ${ }^{10}$

\begin{tabular}{lccccccc}
\hline & \multicolumn{3}{c}{ Con primarias } & & \multicolumn{3}{c}{ Sin primarias } \\
\cline { 2 - 3 } & Ganador & Perdedor & Subtotal & & Ganador & Perdedor & Subtotal \\
\hline \multirow{2}{*}{ Incumbente } & 23 & 9 & 32 & & 57 & 31 & 88 \\
& $(71,2 \%)$ & $(28,8 \%)$ & $(100 \%)$ & & $(64,8 \%)$ & $(35,2 \%)$ & $(100 \%)$ \\
\multirow{2}{*}{ Desafiante } & 54 & 56 & 110 & & 32 & 70 & 102 \\
& $(49,1 \%)$ & $(50,9 \%)$ & $(100 \%)$ & & $(31,4)$ & $(68,6 \%)$ & $(100 \%)$ \\
\multirow{2}{*}{ Total } & 77 & 65 & 142 & & 89 & 101 & 190 \\
& $(54,2 \%)$ & $(45,8 \%)$ & $(100 \%)$ & & $(46,8 \%)$ & $(53,2 \%)$ & $(100 \%)$ \\
\hline
\end{tabular}

Fuente: Elaboración propia con datos de www.servel.cl y www.elecciones.gov.cl

En lo que sigue probamos las dos hipótesis. Por un lado, el efecto de las primarias sobre la elegibilidad de los candidatos. Por otro, el efecto de la participación sobre la elegibilidad de los candidatos. Para ello construimos una tipología de 4 valores considerando el resultado que tuvieron los candidatos de la Concertación en la elección general: incumbentes ganadores, incumbentes perdedores, desafiantes ganadores y desafiantes perdedores. Como dijimos, nuestro objetivo es medir el efecto que tienen las primarias y las variaciones en la participación electoral sobre tales resultados. Para esto, diseñamos un modelo de regresión probit para cada grupo. Incluimos como variables independientes si el candidato

10 La sumatoria general de la Tabla arroja 332 comunas. El total nacional es de 345. La diferencia se explica por la ausencia de candidato a alcalde de la Concertación en 13 comunas. 
compitió en una primaria, las variaciones en la participación electoral comparando 2008 y 2012, el porcentaje de votos que obtuvo la Concertación en la elección de alcaldes de 2008, el número de electores de cada comuna y el porcentaje de pobres de esa comuna, estas dos últimas solo como variables de control. Para el caso de los desafiantes, se incluye una variable dummy que indica si se enfrentó o no a un alcalde incumbente.

Para la hipótesis a), los resultados del modelo indican que las primarias tuvieron un efecto positivo sobre la elegibilidad de los candidatos y especialmente de los desafiantes. Las probabilidades de ganar de un desafiante que enfrentó una primaria son sustantivamente más altas que aquellos desafiantes que no se sometieron a primarias. Naturalmente, esas probabilidades son más altas cuando enfrenta una competencia abierta. Es decir, sin incumbentes. Son más bajas, en cambio, cuando debe enfrentar a un incumbente. De todos modos, la primaria parece facilitar su éxito. Por el contrario, si ese desafiante no enfrentó una primaria, hay mayores probabilidades de ser derrotado en la municipal. Da igual si enfrentó a un incumbente o si la comuna fue de competencia abierta.

Para los incumbentes, en tanto, la interpretación es diferente. El hecho de haber competido en una primaria no incide en el caso de los incumbentes que ganaron en la municipal, pero sí en el caso de los incumbentes que perdieron en la municipal. Seguramente, los incumbentes perdedores ya venían debilitados de la elección municipal anterior y buscaron evitar las primarias para no ser derrotados tan tempranamente. Esto, al menos, les entregó un plazo mayor para desarrollar la campaña e intentar revertir el eventual resultado. Sin embargo, los datos indican que en muchos casos esto no fue posible. Si bien estos incumbentes evitaron la primaria, de todas formas terminaron derrotados en la municipal.

Para la hipótesis b), las variaciones en la participación tuvieron efectos diferenciados para incumbentes y desafiantes. En el caso de los incumbentes, las variaciones en la participación no incidieron significativamente en su éxito electoral. En el caso de los desafiantes, en tanto, una mayor participación aumentó sus probabilidades de derrota, mientras que una caída de la participación aumentó las posibilidades de triunfo.

El Gráfico 8 muestra una simulación estadística para desafiantes ganadores y perdedores según las variaciones en la participación electoral y comparando a candidatos que compitieron en primarias con aquellos que no compitieron en primarias. ${ }^{11}$ Como se advierte, la relación entre participación y probabilidad de éxito de un desafiante es negativa. Es decir, a mayor participación, menor probabilidad de que un desafiante triunfe. Hay diferencias, eso sí, entre desafiantes que enfrentaron una primaria y desafiantes que no enfrentaron una primaria. La línea negra indica la probabilidad de triunfo de un desafiante que fue a primarias. Esta línea está significativamente por sobre la línea gris (desafiantes que no fueron a primarias). Por tanto, es más o menos evidente que los desafiantes sometidos a primarias tienen mayor probabilidad de éxito.

Lo anterior puede obedecer a lo siguiente. Los desafiantes están obligados a movilizar electores. Si enfrentan a incumbentes debilitados o a otro desafiante de baja calidad,

11 La simulación fue hecha con el paquete clarify de Stata. Se llevan a su valor constante todas las variables del modelo, excepto las variaciones en la participación. 
lo más probable es que la participación se deprima. O el incumbente no es capaz de movilizar, o la baja calidad de los desafiantes obstaculiza una amplia movilización de electores. En consecuencia, para ambos casos podría existir una baja percepción de competencia, lo que se traduce en bajos niveles de participación.

Tabla 6. Modelos de regresión probit. La variable dependiente es el tipo de candidato de la Concertación

\begin{tabular}{lcccc}
\hline & $\begin{array}{c}\text { Incumbentes } \\
\text { ganadores }\end{array}$ & $\begin{array}{c}\text { Incumbentes } \\
\text { perdedores }\end{array}$ & $\begin{array}{c}\text { Desafiantes } \\
\text { ganadores }\end{array}$ & $\begin{array}{c}\text { Desafiantes } \\
\text { perdedores }\end{array}$ \\
\hline Cambio\% participación 2008/2012 & -0.006 & 0.010 & -0.016 & 0.015 \\
& $(0.74)$ & $(1.06)$ & $(2.13)^{*}$ & $(2.27)^{*}$ \\
Comunas con primarias (1=Sí; 0=No) & -0.171 & -0.485 & 0.514 & -0.362 \\
& $(1.04)$ & $(2.23)^{*}$ & $(3.23)^{* *}$ & $(2.45)^{*}$ \\
\% de votos Concertación 2008 & 0.017 & 0.020 & -0.003 & -0.011 \\
& $(3.12)^{* *}$ & $(2.82)^{* *}$ & $(0.49)$ & $(2.24)^{*}$ \\
Presencia de un incumbente & - & - & -1.015 & 0.323 \\
(1=Incumbente; 0= Competencia abierta) & & & $(4.76)^{* *}$ & $(1.54)$ \\
Padrón 2012 & -0.000 & -0.000 & -0.000 & 0.000 \\
& $(1.78)$ & $(1.66)$ & $(0.70)$ & $(1.58)$ \\
\% de pobres 2011 & -0.023 & 0.038 & 0.011 & 0.011 \\
& $(2.17)^{*}$ & $(3.22)^{* *}$ & $(1.13)$ & $(1.24)$ \\
Constante & -0.956 & -2.283 & -0.225 & 0.209 \\
Observaciones & $(2.99)^{* *}$ & $(5.26)^{* *}$ & $(0.63)$ & $(0.63)$ \\
\hline
\end{tabular}

Fuente: Elaboración propia con datos de www.servel.cl y www.elecciones.gov.cl

Gráfico 8. Probabilidad de pertenecer al grupo de desafiantes ganadores según realización de primarias y cambio en la participación electoral

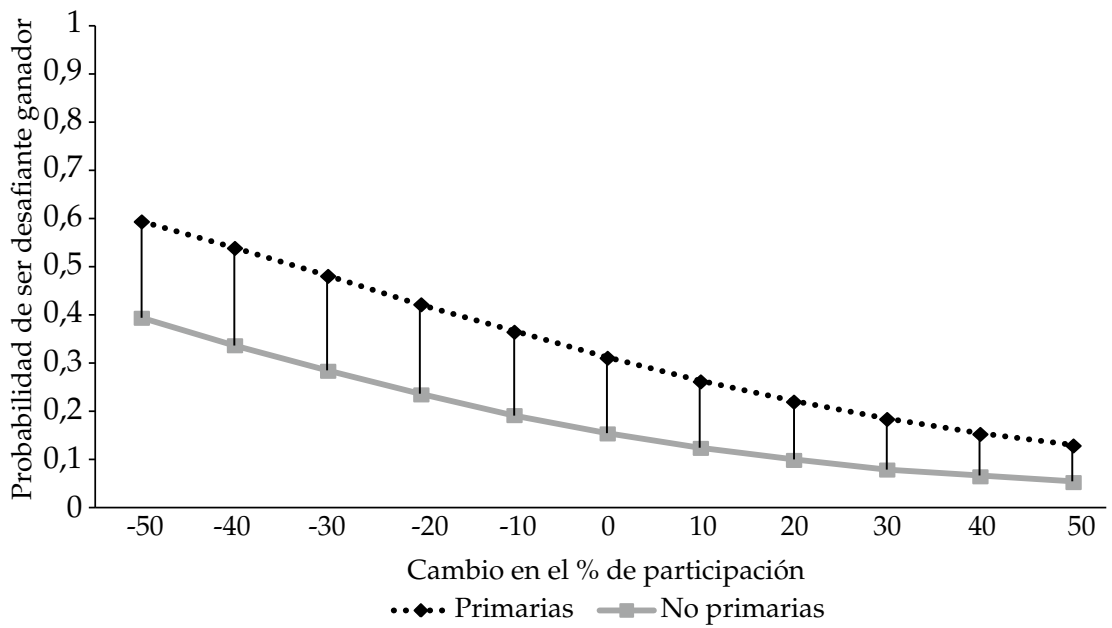

Fuente: Elaboración propia con datos de www.servel.cl y www.elecciones.gov.cl 


\section{IMPLICANCIAS Y CONCLUSIONES}

En este artículo hemos desarrollado un argumento alternativo respecto del efecto de las primarias en la democracia. Sostenemos que las primarias no necesariamente estimulan la participación electoral y que, si bien sirven como un mecanismo de selección de candidatos, el efecto positivo sobre la elegibilidad aplica casi exclusivamente para los desafiantes. Todo parece indicar que en el caso de los incumbentes las primarias se usan más como un instrumento de legitimación que como una instancia genuinamente competitiva. Sin embargo, es justo decir que los incumbentes derrotados, en general, no enfrentaron un proceso de primarias. Esto lo evaluamos tanto en el análisis de datos como en las entrevistas a informantes claves.

En términos más específicos afirmamos, en primer lugar, que la participación en las elecciones primarias está determinada por el tamaño de la comuna, por su nivel socioeconómico (índice de desarrollo humano), por la participación de incumbentes, y por la competitividad. En síntesis, la participación fue más alta en las comunas pequeñas, en las comunas pobres, en las comunas donde compitió un incumbente y en las comunas donde el resultado fue más estrecho. Si bien es cierto que la presencia de incumbentes favorece la participación, esto depende del nivel de competitividad. Cuando el incumbente arrasa, la participación es baja. Cuando el incumbente gana o pierde por estrecho margen, la participación tiende al alza. En otras palabras, cuando el incumbente y el desafiante movilizan ciudadanos para ganar la elección, naturalmente la participación aumenta. En cambio, cuando el incumbente enfrenta a desafiantes débiles, la participación tiende a la baja, pues la movilización electoral solo corre por cuenta del incumbente.

En segundo lugar, sostenemos que las comunas donde se hicieron primarias presentan un nivel de participación muy similar al de las comunas donde no se hicieron primarias. En consecuencia, el hecho de realizar primarias no explica las variaciones en la participación electoral. Lo que sí es cierto es que al considerar solamente las 141 comunas donde se hicieron primarias, a mayor participación en las primarias, mayor participación en la elección municipal de octubre. Es decir, hay comunas donde la participación es sistemáticamente alta y, por tanto, no sorprende que dicha participación haya sido alta en esas comunas. En realidad, el nivel de participación que estas comunas registraron en 2012 no obedece a la realización de primarias. Más bien son comunas donde la participación también fue alta en elecciones anteriores.

En tercer lugar, advertimos que aquellos candidatos desafiantes que previamente compitieron en una primaria tienen mayores probabilidades de ganar respecto de aquellos candidatos desafiantes que no enfrentaron una primaria. Ciertamente, las probabilidades aumentan cuando ese desafiante enfrenta una competencia abierta. Es decir, sin incumbentes. Al comparar a desafiantes que enfrentan a un incumbente y a desafiantes que enfrentan una competencia abierta, siempre el desafiante que compitió en una primaria tiene mayores probabilidades de ganar en la elección general. 


\section{REFERENCIAS}

Abramowitz, Alan I. 1989. "Viability, Electability, and Candidate Choice in a Presidential Primary Election: A Test of Competing Models". Journal of Politics 51 (4): 977-992.

Adams J., y S. Merrill. 2008. "Candidate and Party Strategies in Two-Stage Elections Beginning with a Primary". American Journal of Political Science 52 (2): 344-359.

Agranov, Marina. 2012. "Flip-Flopping, Intense Primaries and the Selection of Candidates". Working paper. Disponible en http://hss.caltech.edu/ magranov/documents/primaries.pdf

Alcántara Sáez, M. 2002. “Experimentos de Democracia Interna: Las Primarias de Partidos en América Latina". University of Notre Dame Kellogg Institute for International Studies Working. Paper Nº 293.

Altman, David. 2012. "Universal Party Primaries and General Election Outcomes: The Case of Uruguay (1999-2009)". Parliamentary Affairs (Mayo): 1-22.

América Economía. 2013. "Maduro cree que primarias para municipales habrían dejado al chavismo partido en pedazos". Publicado el 16 de agosto 2013. Revisado el 30 de mayo 2014. Disponible en: http://www.americaeconomia.com/politica-sociedad/politica/ maduro-cree-que-primarias-para-municipales-habrian-dejado-al-chavismo-par

Auth, Pepe. 2005. “Las primarias en la Concertación. Un camino sin retorno". Agenda Pública 7 (4): 10-15.

Barreda, Mikel. 2004. "Un desafío del desarrollo en América Latina: La democracia interna de los partidos". Gobernanza: 2-5.

Boix, Carles. 1998. "Las elecciones primarias en el PSOE. Ventajas, Ambigüedades y Riesgos". Claves de razón práctica 83: 34-38.

Boyd, Richard. 1989. "The Effects of Primaries and Statewide Races on Voter Turnout". Journal of Politics 51 (3): 730-739.

Brady, David; Hahrie Han y Jeremy C. Pope. 2007. "Primary Elections and Candidate Ideology: Out of Step with the Primary Electorate? Legislative Studies Quarterly 32 (1): 79-105.

Brieba, Daniel. 2013. "¿Las primarias pagan doble? o triple". La Tercera, edición del 20 de enero de 2013. Bruhn, Kathleen. 2010. "Too Much Democracy? Primaries and Candidate Success in the 2006 Mexican National Elections". Latin American Politics and Society 52 (4): 25-52.

Bustamante, Guillermo. 2012. "Triunfo de Boccazzi fue ratificado por TER". Diario Electrónico Magallanews, edición 23 de abril 2012. Disponible en: http://www.elmagallanews.cl/noticia/ politica/triunfo-de-boccazzi-fue-ratificado-por-ter

Buquet, Daniel y Daniel Chasquetti. 2008. "Presidential Candidate Selection in Uruguay, 1942 to 2004". En Pathways to Power. Political Recruitment and Candidate Selection in Latin America, editado por Peter Siavelis y Scott Morgenstern, 316-342. Pennsylvania: Pen State University Press.

Buquet, Daniel y Rafael Piñeiro. 2011. "Participación Electoral en las Elecciones Primarias en Uruguay". Revista Debates 5 (2): 79-95.

Carey, John. 2008. "El Bono de las Primarias en América Latina". En Reforma de los Partidos Políticos en Chile, editado por Arturo Fontaine, Cristián Larroulet, Jorge Navarrete e Ignacio Walker, 429-448. Santiago: CEP, LyD, Proyectamérica y CIEPLAN.

Carey, John y John Polga-Hecimovich. 2006. "Primary Elections and Candidate Strength in Latin America". The Journal of Politics 68 (3): 530-543.

Carty, R. Kennedy y Munroe Eagles. 2003. "Local Conflict within National Parties: The Case of Canada". Paper presented at the Annual Meeting of the American Political Science Association, Philadelphia.

Colomer, Josep M. 2002. “Las elecciones primarias presidenciales en América Latina y sus consecuencias políticas". En El Asedio a la Política. Los Partidos Políticos en América Latina en la Era Neoliberal, editado por Marcelo Cavarozzi y Juan Manuel Abal Medina, 117-134. Buenos Aires: Gedisa.

Contreras, Gonzalo, Alfredo Joignant y Mauricio Morales. 2014. "The Return of Censitary Suffrage? The Effects of Automatic Voter Registration and Voluntary Voting in Chile". Working paper. Observatorio Político Electoral, UDP.

De Luca, Miguel, Mark P. Jones y María Inés Tula. 2002. “Back Rooms or Ballot Boxes? Candidate Nomination in Argentina". Comparative Political Studies 35 (4): 413-436. 
Downs, Anthony. 1957. An Economic Theory of Democracy. New York: Harper \& Row.

Freidenberg, Flavia. 2003. "Selección de candidatos y democracia interna en los partidos de América Latina". Biblioteca de la Reforma Política Nº1. Asociación Civil Transparencia y International IDEA, Lima. Geer, John G. 1988. "Assessing the Representativeness of Electorates in Presidential Primaries". American Journal of Political Science 32 (4): 929-945.

Gelman, Andrew y Gary King. 1990. "Estimating Incumbency Advantage without Bias". American Journal of Political Science 34 (4): 1142-1164.

Gerber, E. y Morton, R. B. 1998. "Primary Election Systems and Representation". The Journal of Law, Economics, and Organization 14: 304-324.

Grofman, Bernard, Guillermo Owen y Christian Collet. 1995. "Rethinking the Partisan Effects of Higher Turnout: So What's the Question?". Public Choice 99: 357-376.

Indridason, Indrioi y Gunnar H. Kristinsson. 2014. "Primary consequences. The Effects of Candidate Selection through Party Primaries in Iceland". Party Politics, forthcoming.

Indridason, Indrioi. 2008. "Competition and Turnout: The Majority Run-off as a Natural Experiment". Electoral Studies 27 (4): 699-710.

Jackman, Robert W. y Ross A. Miller. 1995. "Voter Turnout in the Industrial Democracies during the 1980s". Comparative Political Studies 27: 467-492.

Jackman, Robert W. 1987. "Political Institutions and Voter Turnout in the Industrial Democracies". American Political Science Review 81: 405-423.

Jackson, Matthew, Laurent Mathevet y Kyle Mattes. 2007. "Nomination Processes and Policy Outcomes". Quarterly Journal of Political Science (2): 67-92.

Jacobson, Gary C. 1981. "Incumbents' Advantages in the 1978 U.S. Congressional Elections”. Legislative Studies Quarterly 6 (2): 183-200.

Johnston, Richard, J. Scott Matthews y Amanda. Bittner. 2007. "Turnout and the party system in Canada, 1988-2004". Electoral Studies 26 (4): 735-745.

Kanthak, Kristin y Rebecca B. Morton. 2003. "Primaries and Turnout". Paper presented at the Columbia University Conference on Elections, October 2002.

Kaufmann, Karen, James Gimpel y Adam Hoffman. 2003. "A Promise Fulfilled? Open Primaries and Representation". The Journal of Politics 65 (2): 457-476.

Keele, Luke. 2007. "Social Capital and the Dynamics of Trust in Government". American Journal of Political Science 51 (2): 241-254.

Kemahlioglu, Ozge; Rebecca Weitz-Shapiro y Shigeo Hirano. 2009. "Why Primaries in Latin American Presidential Elections?". The Journal of Politics 71 (1): 339-352.

Kenney, Patrick y Tom W. Rice. 1985. "Voter Turnout in Presidential Primaries: A Cross-Sectional Examination". Political Behavior 7 (1): 101-112.

Kenig, Ofer. 2009. “The Democratization of Party Leader's Selection Methods: Canada in Comparative Perspective". Artículo preparado para la Conferencia anual de la Canadian Political Science Association.

Key, V. O. 1947. Politics, Parties and Pressure Groups. Nueva York: Thomas Y. Crowell Company.

Langston, Joy. 2009. "The Dinosaur that did not Die: Mexico's PRI". Working paper.

Lengle, James. 1981. Representation and Presidential Primaries. Westport, CT: Greenwood.

Lengle, J. I., Owen, D. y Sonner, M. 1995. "Divisive Nominating Mechanisms and Democratic Party Electoral Prospects". Journal of Politics 57: 370-383.

Lijphart, Arend. 1997. “Unequal Participation: Democracy's Unresolved Dilemma”. The American Political Science Review 91 (1): 1-14.

Mainwaring, Scott y Timothy R. Scully. 1995. Building Democratic Institutions. Stanford: Stanford University Press.

McCann, James. 1995. "Nomination Politics and Ideological Polarization: Assessing the Attitudinal Effects of Campaign Involvement". Journal of Politics 57 (1): 101-120.

McGhee, Eric. 2014. "Voter Turnout in Primary Elections". Public Policy Institute of California. Disponible en: http://www.ppic.org/content/pubs/report/R_514EMR.pdf

Mikulska, Anna y Susan Scarrow. 2010. "Assesing the Political Impact of Candidate Selection Rules: Britain in the 1990s". Journal of Elections, Public Opinion and Parties 20 (3): 311-333. 
Moon, Woojin. 2006. “The Paradox of Less Effective Incumbent Spending: Theory and Test". British Journal of Political Science 36: 705-721.

Morgenstern, Scott y Peter M. Siavelis (Eds). 2008. Pathways to Power: Political Recruitment and Candidate Selection in Latin America. Pennsylvania: The Pennsylvania State University Press.

Navarrete, Bernardo. 2005. "Las primarias como mecanismo de selección de candidatos. La experiencia de 1993". Agenda Pública 7 (4): 20-26.

Navia, Patricio y Priscila Rojas. 2008. "El efecto de la participación electoral en las primarias para la elección presidencial de 1999 en Chile". Postdata (13): 193-222.

Payne, J. Mark, Daniel Zovatto, Fernando Carrillo Flórez y Andrés Allamand. 2006. La política importa. Democracia y desarrollo en América Latina. Washington D.C: BID.

Pennings, Paul y Reuven Hazan. 2001. "Democratizing Candidate Selection. Causes and Consequences". Party Politics 7 (3): 267-275.

Polsby, Nelson W. 1983. Consequences of Party Reform. Nueva York: Oxford University Press.

Rahat, Gideon y Reuven Y. Hazan. 2001. "Candidate Selection Methods. An Analytical Framework". Party Politics 7 (3): 297-322.

Rahat, Gideon. 2009. "Which Candidate Selection Method is the Most Democratic?". Government and Opposition (44): 68-90.

Ramiro, Luis. 2014. "Effects of Party Primaries on Electoral Performance: The Spanish Socialist primaries in Local Elections". Party Politics, forthcoming.

Ranney, Austin. 1968. "Representativeness of Primary Electorates". Midwest Journal of Political Science 12: 224-238.

Serra, Gilles. 2008. "Why primaries? The Strategic Choice of a Candidate Selection Method". Working paper. Serra, Gilles. 2011. "Why primaries? The Party's Trade Off Between Policy and Valence". Journal of Theoretical Politics 23 (1): 21-51.

Simonovits, Gábor. 2012. "Competition and turnout revisited: The Importance of Measuring Expected Closeness Accurately". Electoral Studies 31 (2): 364-371.

Toro, Sergio y Daniela García. 2008. “Mecanismos de selección de candidatos para el Poder Legislativo: Un examen a las lógicas de mayor y menor inclusión", en Reforma de los Partidos Políticos en Chile, editado por Arturo Fontaine, Cristián Larroulet, Jorge Navarrete e Ignacio Walker, 395-412. Santiago: CEP, LyD, Proyectamérica y CIEPLAN.

Trounstine, Jessica. 2014. "Turnout and Incumbency in Local Elections". Urban Affairs Review, por aparecer. Valdez, Andrés; Rosa Camacho y Job Miramontes. 2010. "La valía de las primarias. Un estudio sobre el impacto de las precampañas en el resultado de la elección constitucional en México". Revista Enfoques 8 (13): 107-118.

Wuhs, Steven T. 2008. Savage Democracy: Institutional Change and Party Development in Mexico. University Park: Pennsylvania State University Press.

Carlos Cantillana Peña es cientista político y coordinador del Observatorio Político-Electoral de la Universidad Diego Portales, Chile.

E-mail: cantillana.carlos@gmail.com.

Gonzalo Contreras Aguirre es cientista Político e investigador del Observatorio Político-Electoral de la Universidad Diego Portales, Chile.

E-mail: gonzalocontreras.ag@gmail.com.

Mauricio Morales Quiroga es académico de la Escuela de Ciencia Política de la Universidad Diego Portales, Chile. Director del Observatorio Político-Electoral.

E-mail: mauricio.moralesq@mail.udp.cl. 